\title{
Successful Bony Healing For An Adult Patient With Isthmic Spondylolysis At Terminal Stage After Conservative Treatment: A Case Report
}

This article was published in the following Dove Press journal: Journal of Pain Research

\author{
Jinwei Ying $\mathbb{D}^{\prime}$ \\ Lisheng Hou ${ }^{2}$ \\ Honglin Teng' \\ 'Department of Orthopedic Surgery, The \\ First Affiliated Hospital of Wenzhou \\ Medical University, Wenzhou, Zhejiang, \\ People's Republic of China; ${ }^{2}$ Department \\ of Orthopedic Surgery, The Sixth Medical \\ Center of PLA General Hospital, Beijing, \\ People's Republic of China
}

Purpose: Spondylolysis, a defect or fracture of the pars interarticularis due to mechanical stress, is a common cause of lower back pain (LBP) in children and adolescents. Although conservative treatment has been shown to be most effective for young patients at early or progressive stage, few studies have reported the outcomes of conservative treatment for adult spondylolysis at terminal stage. We present the possibility of bony healing in the isthmic defect at terminal stage after conservative treatment.

Patients and methods: A 50-year-old male patient complaining of moderate LBP was diagnosed as having L5 bilateral pars defect accompanied with related grade I spondylolisthesis though radiological evaluation. Magnetic resonance imaging revealed the sclerotic change in the defect of the isthmus, indicating spondylolysis at the terminal stage. This patient was treated with conservative management including lower back muscle functional exercises and medication when necessary.

Results: After five years of follow-up, the patient had a good recovery without reoccurrence. The repeated radiography and computed tomography demonstrated the pars defect had disappeared and been replaced by trabeculation, with no evidence of progressive segmental instability or vertebrae slip.

Conclusion: Symptomatic adult patients with isthmus spondylolysis at terminal stage might still have an opportunity to be effectively managed with rigorous conservative treatment for obtaining bony healing. However, the progression of listhesis or persistent debilitating pain should warrant consideration for surgical treatment.

Keywords: spondylolisthesis, isthmus, pars interarticularis, lower back pain, bony union

\section{Introduction}

Lumbar spondylolysis is the pathological condition of unilateral or bilateral bone defect in the pars interarticularis, which may permit forward slippage of the upper vertebra and progress to spondylolisthesis. ${ }^{1,2}$ This structural defect typically causes disabling lower back pain (LBP) in adolescents, but is rarely associated with neurological symptoms because the slippage of the vertebral body hardly causes lumbar stenosis or nerve compression. ${ }^{3-5}$ The bony defect was classified into three stages based on the plain radiograph or computed tomography (CT) scanning as previously described: the early stage was defined as a hairline defect; in the progressive stage, the fracture had progressed to a wider gap with the presence of small fragments; and in the terminal stage, the defect was characterized as sclerotic change or pseudoarthrosis. ${ }^{6,7}$ With the development of magnetic resonance imaging

Honglin Teng

Department of Orthopedic Surgery, The First Affiliated Hospital of Wenzhou Medical University, Nanbaixiang Street, Ouhai, Wenzhou 325000, Zhejiang,

People's Republic of China

Tel +8657755979391

$\mathrm{Fax}+861055979391$

Email907173102@qq.com 
(MRI), some other investigators supplemented "very early" stage before the three stages, in which no fracture line was visible, but a signal intensity change was detected at the adjacent pedicle on short tau inversion recovery (STIR) images, which was regarded as a stress reaction on the lamina. ${ }^{8,9}$

Although high bony healing rates could be observed among pediatric and adolescent spondylolysis patients at early or progressive stage after conservative treatment, ${ }^{6,9-14}$ to our knowledge, successful conservative treatment for adult spondylolysis at the terminal stage has not been reported before. In this report, we describe an adult patient with the terminal defect of the pars interarticularis at L5 who had satisfactory bony healing after long-term conservative management.

\section{Case Report}

A 50-year-old male patient, working as a high school teacher, mainly complained of moderate LBP for more than 2 weeks. He had no smoking or drinking history. In his life, he liked reading and had no favorite physical activity. Before admission, his BMI was $24.5\left(\mathrm{~kg} / \mathrm{m}^{2}\right)$. On physical examination, he had moderate tenderness and percussive pain on the lumbosacral region. Plain films showed bilateral defects of the pars interarticularis at L5 accompanied by grade I spondylolisthesis, and spina bifida occulta (SBO) at L5 and S1 with isolated spinous processes (Figure 1). CT sagittal two-dimensional reconstruction and transverse section showed the sclerotic change in the defects of the pars interarticularis at L5 (Figure 2). MRI demonstrated low signal intensity in the isthmic defects on T1-, T2-weighted and STIR images, but no nerve compression or canal stenosis occurred at the level of L5-S1. Besides, the degenerative degree of L5S1 intervertebral disc (IVD) was evaluated at Pfirrmann III (Figure 3).

At first, bed rest and painkilling drugs took effect. Two months later, he returned to normal daily work and paid attention to keeping a good posture and the avoidance of heavy physical labor. During his daily activities, the patient was also encouraged to undertake some isometric exercises to maintain and strengthen the back muscles. In spite of occasionally intermittent reoccurrence, the symptoms were quickly alleviated or disappeared. After 5 years, his BMI decreased slightly to $23.2\left(\mathrm{~kg} / \mathrm{m}^{2}\right)$, the radiographic re-examination showed the gap between the separated parts had disappeared and had been replaced by trabeculation while the healed isthmus became elongated
(Figure 4). Furthermore, repeated CT images confirmed the satisfying bony union of the bilateral defects without progressive spondylolisthesis (Figure 5). Because there were no neurological symptoms, the patient refused to undergo MRI, meaning that the degenerative degree of the affected IVD at the end of follow-up could not be evaluated.

This case report was approved by the Institutional Ethical Committee of First Affiliated Hospital of Wenzhou Medical University. The patient provided written informed consent to have his case details and accompanying images published.

\section{Discussion}

Young patients with spondylolysis and low-grade spondylolisthesis commonly have a benign prognosis after conservative management. ${ }^{15}$ Whenever conservative treatment fails, surgical stabilization and fusion is advisable. ${ }^{16}$ Although there have been some studies of successful bone healing in pediatric and adolescent patients with spondylolysis, ${ }^{6,9-14}$ the responses to conservative treatment were varied considerably. Fujii et al. ${ }^{7}$ attempted to identify the radiological variables which might influence the success rate of bone healing for isthmic defect and concluded that the stage of the defect was the most predominant predictor. Morita et al. ${ }^{6}$ studied the effects of conservative management on 185 adolescents with spondylolysis and found a significant correlation between successful bony union and the stage of the defect. Sakai et al. ${ }^{9}$ performed a similar study on 60 pediatric patients and found $100 \%$ healing at very early stage, $93.8 \%$ healing at early stage, and $80 \%$ healing at progressive stage, but they did not attempt to perform conservative treatment for spondylolysis patients at terminal stage. These results suggest that early diagnosis and treatment of spondylolysis will improve the prognosis.

In adult spondylolysis patients, successful bony healing for the defect at terminal stage after conservative treatment was rarely reported. Previously, Sulla et al. ${ }^{17}$ reported an adult male with traumatic cervical spondylolysis and spondylolisthesis obtained spontaneous healing without surgery after 7 years of the injury. Given the present symptoms of manifesting tolerable back pain without neurological deficits in this case, we firstly decided to perform non-surgical treatment targeting relief of the main symptoms. Fortunately, in addition to the resolution of symptoms, radiological evaluation demonstrated satisfying bony healing in the sclerotic defects. This indicates that spontaneous 

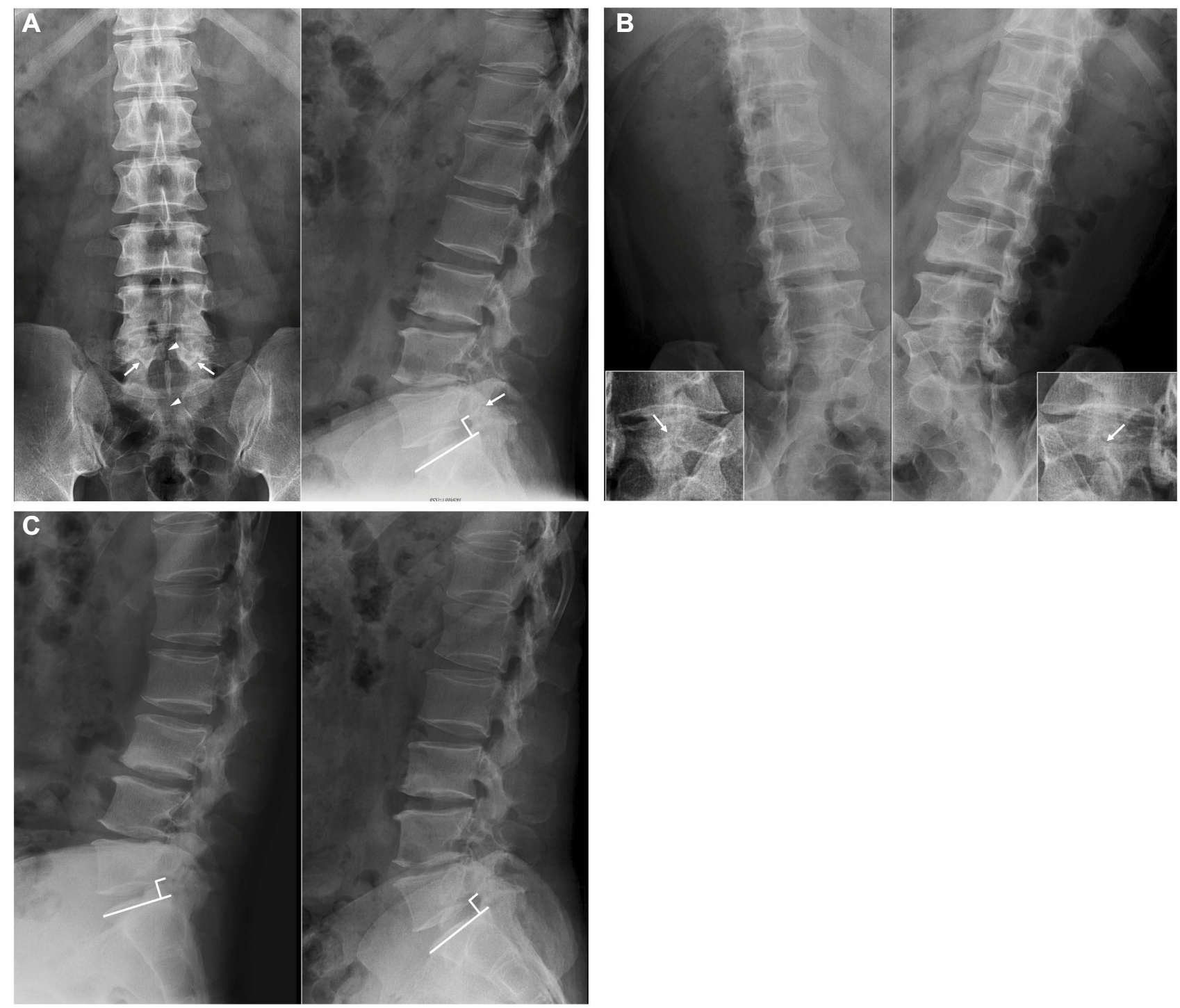

Figure I Lumbar plain radiographs of the 50 -year-old male patient at his first visit to our orthopedic clinic.

Notes: (A) Anteroposterior and lateral films showed bilateral defects of the pars interarticularis with grade I spondylolisthesis at L5, and SBO at L5 and SI with isolated spinous processes. (B) Double-oblique films demonstrated bilateral spondylolysis with irregular hardened edge formation. (C) Flexion-extension films revealed no segmental instability. Arrows indicate spondylolysis. Arrowheads indicate SBO.

Abbreviation: SBO, spina bifida occulta.

bony healing could be also obtained for the adult patient with spondylolysis receiving conservative treatment even
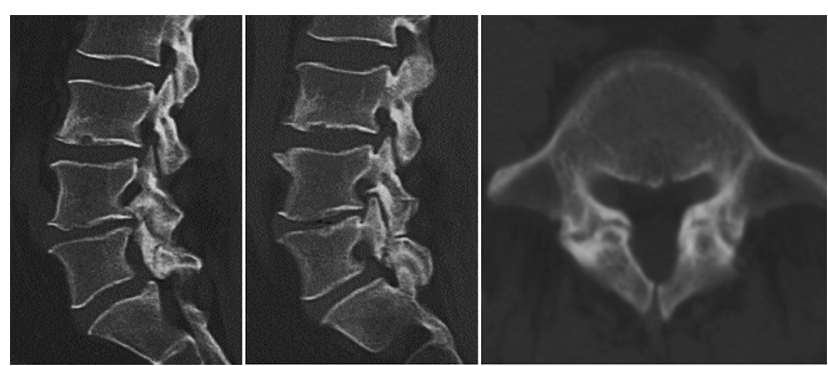

Figure 2 CT scans and sagittal two-dimensional reconstruction of the 50-year-old male patient at his first visit to our orthopedic clinic.

Note: Bilateral isthmic defects with sclerotic change at L5.

Abbreviation: CT, computed tomography. at the terminal stage. However, we must point out that not all separated regions of the pars reached complete healing in this case because some cleft still could be seen in the right side. Besides, it is not certain whether all separated regions would be completely disappeared and the part that had been healed would be strong enough to resist slippage of the vertebral body in the future.

\section{Conclusion}

Symptomatic adult patients with isthmus spondylolysis at terminal stage might still have an opportunity to be effectively managed with rigorous conservative treatment for achieving satisfying bony healing. Decreased BMI, 

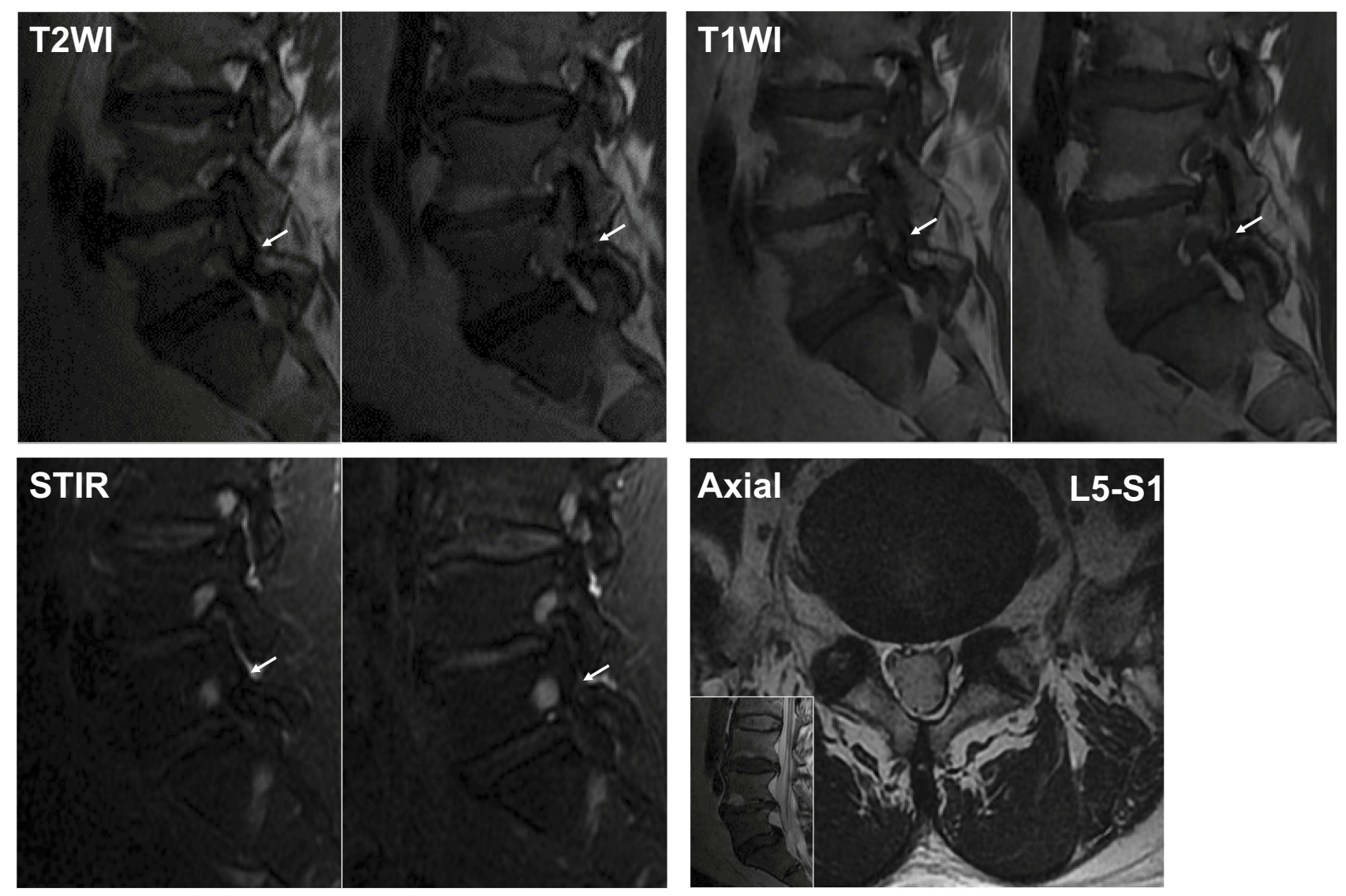

Figure $3 \mathrm{MRI}$ of the 50 -year-old male patient at his first visit to our hospital.

Notes: Low intensities in the bilateral defects of the pars interarticularis at L5 and no nerve compression or canal stenosis at the level of L5-SI. Arrows indicate spondylolysis. Abbreviations: MRI, magnetic resonance imaging; T2WI, T2-weighted image; TIWI, TI-weighted image; STIR, short tau inversion recovery.

relatively healthy disc, restriction of lumbar motion, and strengthening back muscle may be very important for bone healing of the defect of the pars interarticularis. A prospective study with a larger sample size will be needed in the future. However, the progression of related slippage or recurrence of disabling pain with or without neurological
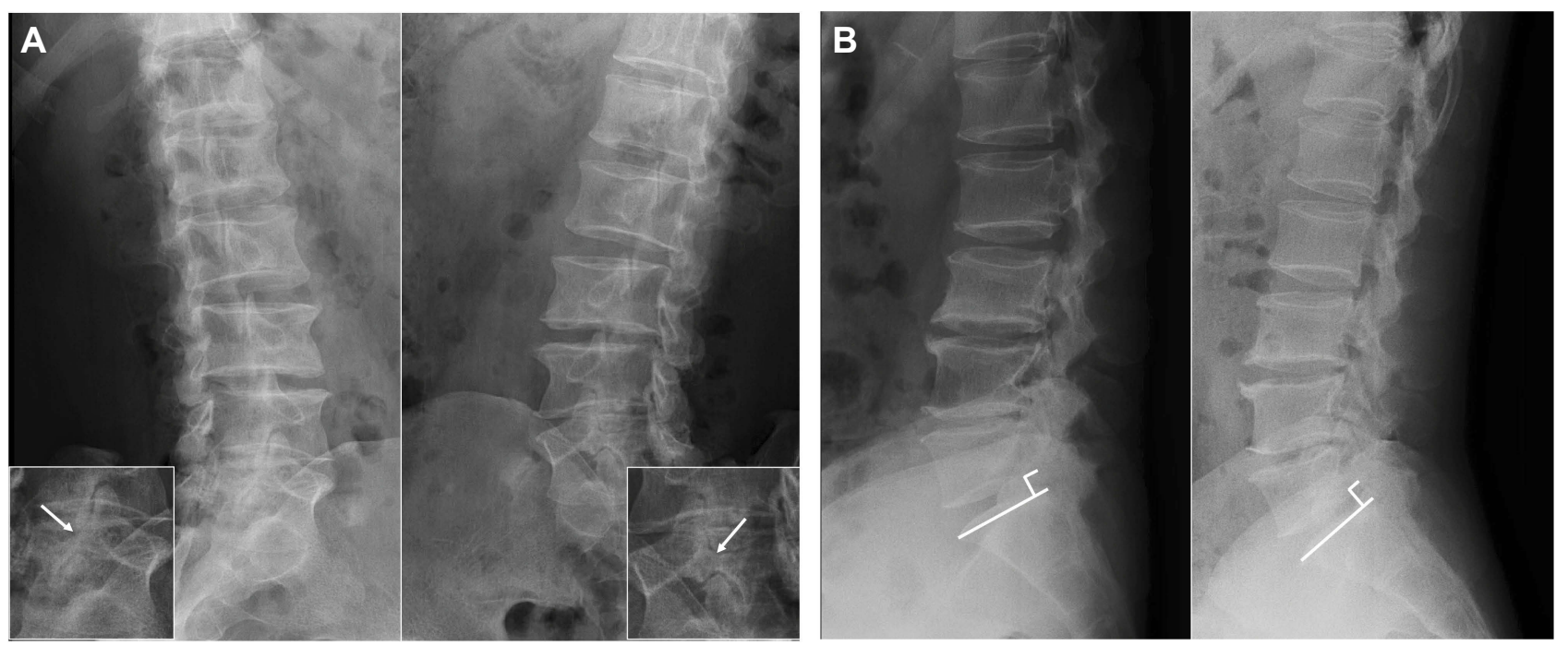

Figure 4 The repeated lumbar radiographs after five-year follow-up.

Notes: (A) Double-oblique views demonstrated the defects of the pars were replaced by trabeculation but still left some sclerotic remnants. (B) Dynamic films demonstrated no progressive instability of the lumbar spine. Arrows indicate the bony healing of the defects of the pars interarticularis. 


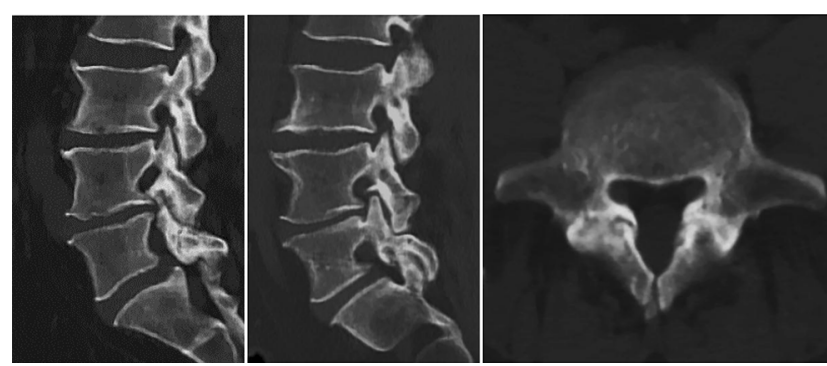

Figure 5 The repeated CT scanning and sagittal two-dimensional reconstruction after 5-year follow-up.

Note: Most of the defects of the isthmus at L5 had satisfactory bony healing and the healed parts of the pars became elongated and narrow, but left a little non-union at the right-hand side.

Abbreviation: $\mathrm{CT}$, computed tomography.

deficits should warrant consideration for surgical stabilization and fusion.

\section{Disclosure}

The authors report no conflicts of interest in this work.

\section{References}

1. Logroscino G, Mazza O, Aulisa G, Pitta L, Pola E, Aulisa L. Spondylolysis and spondylolisthesis in the pediatric and adolescent population. Childs Nerv Syst. 2001;17(11):644-655. doi:10.1007/ s003810100495

2. Smith JA, Hu SS. Management of spondylolysis and spondylolisthesis in the pediatric and adolescent population. Orthop Clin North Am. 1999;30(3):487-499, ix. doi:10.1016/S0030-5898(05)70101-2

3. Tsirikos AI, Garrido EG. Spondylolysis and spondylolisthesis in children and adolescents. J Bone Joint Surg Br. 2010;92(6):751-759. doi:10.1302/0301-620X.92B6.23014

4. Gagnet P, Kern K, Andrews K, Elgafy H, Ebraheim N. Spondylolysis and spondylolisthesis: a review of the literature. J Orthop. 2018;15 (2):404-407. doi:10.1016/j.jor.2018.03.008
5. Tamburrelli FC, Meluzio MC, Burrofato A, Perna A, Proietti L. Minimally invasive surgery procedure in isthmic spondylolisthesis. Eur Spine J. 2018;27:237-243. doi:10.1007/s00586-018-5627-8

6. Morita T, Ikata T, Katoh S, Miyake R. Lumbar spondylolysis in children and adolescents. J Bone Joint Surg Br. 1995;77(4):620625. doi:10.1302/0301-620X.77B4.7615609

7. Fujii K, Katoh S, Sairyo K, Ikata T, Yasui N. Union of defects in the pars interarticularis of the lumbar spine in children and adolescents. The radiological outcome after conservative treatment. J Bone Joint Surg Br. 2004;86(2):225-231. doi:10.1302/0301-620X.86B2.14339

8. Sairyo K, Katoh S, Takata Y, et al. MRI signal changes of the pedicle as an indicator for early diagnosis of spondylolysis in children and adolescents: a clinical and biomechanical study. Spine. 2006;31 (2):206-211. doi:10.1097/01.brs.0000195161.60549.67

9. Sakai T, Tezuka F, Yamashita K, et al. Conservative treatment for bony healing in pediatric lumbar spondylolysis. Spine. 2017;42(12): E716-e720. doi:10.1097/BRS.0000000000001931

10. Wiltse LL, Widell EH Jr., Jackson DW. Fatigue fracture: the basic lesion is inthmic spondylolisthesis. J Bone Joint Surg Am. 1975;57 (1):17-22. doi:10.2106/00004623-197557010-00003

11. Blanda J, Bethem D, Moats W, Lew M. Defects of pars interarticularis in athletes: a protocol for nonoperative treatment. $J$ Spinal Disord. 1993;6(5):406-411. doi:10.1097/00002517-199306 050-00007

12. Steiner ME, Micheli LJ. Treatment of symptomatic spondylolysis and spondylolisthesis with the modified Boston brace. Spine. 1985;10 (10):937-943. doi:10.1097/00007632-198512000-00013

13. Sairyo K, Sakai T, Yasui N, Dezawa A. Conservative treatment for pediatric lumbar spondylolysis to achieve bone healing using a hard brace: what type and how long?: clinical article. J Spine Neurosurg. 2012;16(6):610-614. doi:10.3171/2012.2.SPINE10914

14. Wiltse LL, Newman PH, Macnab I. Classification of spondylolisis and spondylolisthesis. Clin Orthop Relat Res. 1976;117(117):23-29.

15. Lim MR, Yoon SC, Green DW. Symptomatic spondylolysis: diagnosis and treatment. Curr Opin Pediatr. 2004;16(1):37-46. doi:10.1097/ 00008480-200402000-00008

16. O'Brien MF. Low-grade isthmic/lytic spondylolisthesis in adults. Instr Course Lect. 2003;52:511-524.

17. Sulla I, Mach P. [A patient with spontaneous healing of traumatic spondylolisthesis of the cervical vertebrae]. Rozhl Chir. 2001;80 (4):217-219
Journal of Pain Research

\section{Publish your work in this journal}

The Journal of Pain Research is an international, peer reviewed, open access, online journal that welcomes laboratory and clinical findings in the fields of pain research and the prevention and management of pain. Original research, reviews, symposium reports, hypothesis formation and commentaries are all considered for publication. The manuscript management system is completely online and includes a very quick and fair peer-review system, which is all easy to use. Visit http:// www.dovepress.com/testimonials.php to read real quotes from published authors. 